\title{
Addressing Quality Management System Obstacles in Jordanian Hospitals
}

\author{
Ashraf A'aqoulah $^{1}$, Ahmed Bawa Kuyini ${ }^{2}$, Musa T. Ajlouni ${ }^{1}$ \\ ${ }^{1}$ Hospital Management Department, Faculty of Administrative and Financial Sciences, Philadelphia University, Amman, \\ Jordan \\ ${ }^{2}$ School of Health, University of New England, Armidale, NSW, Australia \\ Correspondence: Ashraf A'aqoulah, Hospital Management Department, Faculty of Administrative and Financial \\ Sciences, Philadelphia University, Amman, Jordan. E-mail: ashraf_just_jo@yahoo.com
}

Received: May 31, 2016

Accepted: June 20, 2016

Online Published: July 18, 2016

doi:10.5539/ibr.v9n9p34

URL: http://dx.doi.org/10.5539/ibr.v9n9p34

\begin{abstract}
Quality Management System (QMS) enhances management, allows more effective organisation, improves quality of services, increases staff satisfaction and commitment to the organisation, enhances co-operation among employees and management, and improve patients' satisfaction. Therefore, all hospitals make consistent efforts to address obstacles that face their QMS.

This study aimed to explore Hospital managers' views about how to address QMS obstacles in Jordanian hospitals. The results from semi-structure interviews with 30 managers consisting of general directors, medical directors, administrative directors, quality directors, and nursing directors showed that hospitals can address QMS obstacles through a range of measures including but not limited to rewarding talented employees, providing good salaries and benefits, and recruiting qualified and efficient hospital managers. Recommendations for improving the implementation of QMS in Jordanian hospitals are provided.
\end{abstract}

Keywords: addressing obstacles, quality management system, Jordanian, hospitals

\section{Introduction}

A hospital's Quality Management System (QMS) is defined as the 'procedures explicitly designed to monitor, assess and improve the quality of care in a hospital' (Wagner, Gulacsi, Takacs, \& Outinen, 2006). Implementing a QMS, which is an essential component in the development of a contemporary approach to quality management, can help hospitals create and implement procedures that improve patient and employee satisfaction.

The International Organisation for Standardization (ISO) has started using the implementation of a QMS as a basis for recognition of accreditation in all organizations including hospitals (Hauswirth, 2007). While many hospitals are driven by the stance of the ISO to implement QMS, some have argued that it will be better for hospitals to apply QMS solely because they are motivated by quality improvement (DiMaggio and Powell, 1983; Westphal, Gulati, and Shortell, 1997).

Hospitals in Jordan, like other countries, face many QMS obstacles that impinge on the effective functioning and the provision of quality services. In a study A'aqoulah, Kuyini, Ajlouni, Saif, and Raoush, (2016) found that the QMS obstacles facing Jordanisan hospitals include lack of rewards for staff, inadequate authority delegation, lack of staff training, insufficient staff motivation, inadequate material resources, and insufficient budgetary provisions to maintain QMS in Jordanian hospitals. These QMS obstacles need to be resolved in order for the hospitals to function effectively and provide better quality services.

The literature shows that different approaches are used to resolve QMS obstacles in different contexts. Since each country or hospital is unique it clear that different hospital managers in different countries might have varying approaches to addressing QMS obstacles. In Jordan, the QMS obstacles facing hospitals are somewhat unique and while isolated studies have identified these obstacles, they do not often focus on how to address them across several hospitals. This study therefore aimed to explore the views of hospital managers about how to address the QMS obstacles in their hospitals.

\section{Literature Review}

There is agreement in the literature that successful QMS implementation leads to more effective organisations. Improved management of services leads to increased employee commitment and organisational performance (Nanda, 
2005; Oakland, 2012). However, it is near impossible for hospitals to have perfect quality management systems (QMS). Thus it is to be expected that QMS will experience some obstacles. Researchers in several countries (A'aqoulah et al. 2016; Abdullah, Razak, Hanafi, \& Jaafar, 2013; Lin \& Jang, 2008; Pongpirul, Sriratanaban, Asavaroengchai, Thammatach, \& Laoitthi, 2006) have reported on the existence of obstacles that hinder implementation of a QMS.

A'aqoulah and his colleagues (2016) found that low-performing hospitals in Jordan faced six major obstacles: lack of rewards for hospital staff, inadequate material resources, lack of training programmes in sufficient staff motivation, insufficient budget for a QMS, and inadequate authority delegation. Whereas, the high-performing hospitals faced three major obstacles: lack of rewards for hospital staff, inadequate authority delegation, and shortage of staff. Abdullah et al. (2013) explored the main barriers of ISO 9000 implementation in local government organisations in Malaysia. The study found that there are three main barriers: organisational barriers, resource barriers and behavioural and cultural barriers. In another study, Lin and Jang (2008) empirically examined how organisations in Taiwan have successfully implemented and benefited from QMSs. The findings showed that factors facilitating success of a QMS were four constructs: quality planning, top management support, continuous improvement, and employee involvement. The researchers concluded that an organisation's performance and successful QMS implementation are positively related. Finally, Pongpirul et al. (2006) explored the obstacles that hinder implementation of QMSs in Thailand hospitals based on hospital accreditation standards. The results demonstrated that there were obstacles to QMS such as utilisation and integration of information and quality improvement (QI) requirements.

\section{Method}

\subsection{The Study Population}

The population for this qualitative study consisted of all managers in governmental and private hospitals located in different regions of Jordan. The study participants were 30 managers who worked in six hospitals (three government and three private hospitals) and consisted of: general directors, medical directors, administrative directors, quality directors, and nursing directors. The selection of hospital managers for the interviews was based on purposive sampling technique, resulting in a total of 30 participants.

The prime consideration with the sampling process in this case was to recruit and select informants who could provide a deep understanding of the issues under investigation and to recruit and select them in such a way as to give credibility to the findings so that they can be potentially generalised to another context or a larger population.

\subsection{The Research Tool}

The research tool used in this study was an interview guide consisting of semi-structured questions. The questions focused on the background / experience of the managers and their suggested solutions to address the QMS obstacles identified in their hospitals. Specifically, the interview questions focused on how hospitals can address the QMS obstacles related to: leadership and management, resource management, quality improvement and organisational culture.

\subsection{Data Collection}

After receiving their verbal consent for willingness to participate, a printed information sheet about the QMS obstacles and the study objectives and questions was sent to each participant before the interview. The interview was arranged at a mutually convenient place and time. A consent form was signed by the interviewees before the interviews. Interviews followed a semi-structured format that relied upon central topics when asking questions. The approach to the interview followed an informal conversational style with prompts to get more in-depth information. The interviews varied in length from approximately 45 to 60 minutes. The face-to-face interviews were recorded using a digital recording device. Notes were also taken during the interviews.. The interview process commenced with the following steps: First, introduction, information sheet reading, and informed consent completion; second, the participant was provided with brief information about the QMS obstacles in Jordanian hospitals as reported in previous studies. Then collection of background information and demographic data of the participants; and other, questions and prompts.

\subsection{Data Analysis}

The qualitative data from the 30 interviews was analysed with help of the $\mathrm{N}$ Vivo qualitative data analysis software package. The interviews, which were tape-recorded verbatim were transcribed and reviewed then the data was analysed. Later, the data were imported into the $\mathrm{N}$ Vivo qualitative data analysis software package to assist with linking concepts contained in the data.

This qualitative data analysis utilised methodological principles of thematic analysis. The themes were developed by using a summarised interpretative approach to the data, as described by Wojnar and Swanson (2007). The modelled processes included (1) reading the interviews to obtain an overall understanding, (2) coding for emerging codes in a 
number of cycles, (3) identifying common codes from coded transcripts, (4) clarifying disagreements in interpretation, (5) identifying common themes and patterns and making inferences from them, and (6) selecting sample quotes to illustrate the themes that emerged.

\section{Results}

\subsection{Characteristics of Participants}

More than half of the participants were males (54.2\%). All 30 participants were above 30 years of age; the majority of them were more than 50 years old. Most of the participants were postgraduates. All participants had more than 6 years of work experience; half of them had experience of 11 to 16 years.

\subsection{Themes Related to Addressing QMS Obstacles}

The data analysis showed that the following main themes to address QMS obstacles were brought up by the participants during the interviews:

1. Rewarding talented employees and providing good salaries and benefits

2. Recruiting qualified and efficient hospital managers

3. Delegating authority with clear identification of responsibilities and accountability

4. Building a trusting hospital environment

5. Enhancing employees' morale

6. Employing enough and qualified hospital staff

7. Establishing continuous training programmes with sufficient funds

The following sections detail the views of the hospital managers regarding ways to address QMS obstacles organized according to the above seven themes with examples of statements as reported by those managers.

\subsubsection{Rewarding Talented Employees and Providing Good Salaries and Benefits}

All of the participants mentioned that hospitals should provide good salaries and benefits for employees. They emphasised the importance of a reward system that is fair and compensates talented and highly performing employees. Most participants reported that fair rewards improve hospital performance and increase morale and productivity of employees. The following statements reflect the participants' views related to this theme.

'I am sure that if a hospital provides talented staff fair financial rewards, this will encourage them to give [put in] more effort. . . . I think it is important to support talents.' 'Rewards should not be given only for physicians but also for technicians and other hospital staff.'

'I think that having straightforward reward criteria will improve the level of services provided to patients and motivate staff to apply QMS.'

'I think that all staff are looking for good salaries and work benefits to cover the cost of living; if the hospital provides good salaries and benefits, it can attract the best qualified employees.'

'Increasing salaries and introducing some benefits such as nursery, and extra vacation days will attract qualified hospital staff.'

'Sufficient budgets allow QMSs to reward talented and highly productive employees.'

\subsubsection{Recruiting Qualified and Efficient Hospital Managers}

The participants believed that hospital managers should be qualified and efficient to lead their organizations to success. They indicated that efficient managers should be able to develop clear goals, effective policies and creative procedures. In addition, they should always act as change agents to adopt and implement continuous quality initiatives in order to achieve hospital objectives. All participants agreed that directors should have continuous training programs in management as other professionals. The following statements support the participants' views about this issue.

'A paediatrician for example, may be successful in his speciality but this does not mean that he will be successful as hospital director ... I think the right person to lead a hospital should be qualified in hospital management.'

'People should only do the work that they are trained for; hospital management should be considered as any other health profession like medicine or nursing.'

'Managers should be able to motivate staff to achieve hospital objectives. They should also be able to develop achievable goals and use hospital resources efficiently.'

'I think training programmes for managers are essential to improve their skills in management and leadership. Training 
programmes are important for all staff, especially for managers and decision makers.'

\subsubsection{Delegating Authority with Clear Identification of Responsibilities and Accountability}

Most participants stated that hospital managers should delegate part of their authority to subordinates based on hospital rules and regulations. They assured that delegation motivates people and makes them more powerful and accountable for their decisions.

'If hospital managers delegate part of their authority to their subordinates, the hospital staff will carry the responsibility and they will do their best to improve the quality of services in the hospital.'

'I think delegation of authority makes the staff more powerful to take decisions related to their duties.'

'I believe that quality will be improved if the hospital managers delegate some of their authority to their staff.'

'Hospitals should create accountability systems to match delegated authority for subordinates.'

\subsubsection{Building a Trusting Hospital Environment}

The majority of the participants mentioned that hospital managers should build a trusting environment in their hospitals. They pointed that when mangers create a high consistent trust environment, collaboration increases and hospitals keep progressing. They mentioned that hospital managers should trust and respect all staff in order to build a trusting environment.

'Hospitals should have a trusting environment among all managerial levels'.

'I think creating a trusting environment is important to achieve hospital objectives'. 'Hospital managers should always tell the truth and keep promises.'

'When people believe that hospital management is trustworthy, they are willing to contribute and work hard for achieving hospital goals.'

'If employees perceive that a hospital—or its managers - are less trustworthy, employees become unwilling to contribute effectively to their hospital's well-being beyond the minimum work duties or hours.'

'Hospital managers should trust, support and be fair with all hospital staff irrespective of their professions or titles.'

\subsubsection{Enhancing Employees' Morale}

The majority of the participants indicated that employees' motivation is a key success factor for QMS. They emphasised that employees with higher morale have a better attitude, provide higher service levels and are more productive. Morale incentives can create a friendly atmosphere in hospitals. On the other hand, bad morale reduces efficiency and productivity.

'Employees like to be recognized and have some nice words from hospital managers whenever they achieve positive results. For example, they like to hear some words like 'thank you for your effort' when the hospital gets accreditation or any award.'

'I believe that morale incentives are very important for building friendly relationship between hospital staff and mangers.'

'Every employee should feel that he or she is important for the hospital and that his or her job serves the hospital and contributes to patient care.'

'I really use morale incentives to encourage my staff to do extra duties in an effective way. Morale incentives may include few days off, or even just simple gifts.'

'Hospitals need to embrace incentives which can be remembered, such as gifts, holidays, or a praise and simple verbal thank you.'

\subsubsection{Employing Enough and Qualified Hospital Staff}

All participants stated that hospitals should employ enough and well trained staff to achieve hospital objectives and adapt to the increasing number of patients especially those with chronic diseases. They reported that shortage of qualified staff is a risk and usually associated with poor patient outcomes.

'It is difficult for hospitals to apply QMS and achieve high quality service levels if they have shortage of staff.'

'Hospitals that work under pressure of staff shortage cannot provide proper services to their patients; therefore, they cannot achieve their goals to reach the patient satisfaction and attract more patients.'

'There is a high demand on doctors and nurses; therefore, these two groups are usually overloaded and have more turn-over rates.' 
'Motivating and training hospital staff should be considered as priority to increase productivity and minimize staff turn-over.'

\subsubsection{Establishing Continuous Training Programmes with Sufficient Funds}

Most of the participants stated that for hospitals to grow and provide quality patient care, it is essential to invest in training and staff development.

Not only do training programs help staff avoid making errors but they also help the hospital increase employee retention, gain their loyalty, and ultimately increase productivity. They emphasised the importance of using modern training methods like e-learning and simulation in addition to the traditional methods.

'I believe that hospitals should initiate continuous training programmes and support them with sufficient funds.'

'I think that funding of training programmes should be adequate to train all staff irrespective of their speciality or years of experience.'

'Training programmes should focus on employees who do not have enough experience or those who have low performance levels to improve their productivity and minimize mistakes.'

'Using different training methods (traditional and modern) will improve the effectiveness of training programmes and motivate staff to participate in these programs.'

'Qualified trainers from inside and outside the hospital should be selected to provide in-house training.'

'The hospital should have a continuous training plan with sufficient budget to support in-house training and off-campus training programs including workshops and conferences.'

\section{Discussion}

This study, which aimed at exploring the views of hospital managers in addressing QMS obstacles showed that Rewarding talented employees, and Enhancing staff morale, Recruiting qualified and efficient hospital managers, Delegating authority, Building a trusting work environments, Employing enough and qualified staff, Establishing continuous training programmes are likely to eliminate or reduce QMS obstacles.

These findings if implemented with the support of the Jordan Ministry of Health could lead to efficiency and better services in hospitals. Such a proposition of improved efficiency and services is based on the other findings in the literature. For example Lambrou, Kontodimopoulos, and Niakas (2010) found that hospital managers were able to see improvement in the health service quality and motivation amongst hospital staff members when they initiated a rewards programme. With an ongoing rewards programme, Phillips and Edwards (2008) concluded that the performance level of staff will increase more than before and both employees' job satisfaction and patient satisfaction will be achieved (Phillips \& Edwards, 2008). Sarawat, (2012) also suggests that Hospitals that apply a rewards programme with a balanced combination of training, recognition, benefits, and rewards have the ability to attract more highly skilled employees than other hospitals. Therefore, Jordanian hospitals need to be more effective at recognising and rewarding talented employees.

The participants mentioned that most hospital managers do not have specialized training in hospital management. This happens in spite of the fact that Jordan has undergraduate and graduate university programs in healthcare management (Ajlouni, 2010).

Pillay (2008) argued that a hospital management training programme is important for hospital managers and those who have to make decisions in the health care system. These skills and attributes are essential for managers in Jordanian hospitals if they are to succeed in identifying and resolving QMS obstacles and this can occur through recruiting qualified managers and providing continuous training programs in health management.

Delegation of authority was perceived by participants as an important factor for addressing QMS obstacles. The lack of delegation as indicated by Colombo and Delmastro (2004) and Perrot and Roodenbeke (2011) could affect the relationship between managers and their employees negatively and decrease managers' efficiency. Thus, adopting a proper program for delegation of authority in Jordanian hospitals with clear identification of decision making rights, responsibilities and accountability is highly recommended.

The participants emphasised the importance of building healthy trusting environments between hospital managers and their staff. Natale, Wilson, and Perry (2002) argued that organisation managers should to be creative and proactive to initiate a trusting work environment. To create this environment, managers could use the following procedures: first, managers should prompt employees to talk and express their skills, experiences, and feelings. Second, managers should listen to, learn and value employees' thoughts. Finally, managers need to focus on progress, rather than on perfection. By using such simple and not costly procedures in Jordanian hospitals, managers can build trusting work environments 
and contribute to improving QMS in their hospitals. In order to improve QMSs in Jordanian hospitals, hospital managers should devise measures to improve efficiency through trust, clear accountability measures and providing staff with sufficient opportunities to do their best work in their jobs.

Shortage of staff can negatively affect employees' performance. Nelson (2008) observes that inadequate numbers of staff members, especially nurses, increase the workload for all employees and decrease vigilance and alertness, which could lead to an increase in medical and medication errors. Inadequate staffing levels can also lead to patients receiving unsatisfactory care, raise the risk of aggression and violence from unsatisfied patients, and cause interruptions in much-needed rest and meal breaks (Abele, 2004).

The participants believed that an effective training programme is critical to quality improvement and addressing QMS obstacles. Krupa and Chan (2005) and Kirkpatrick (2009) explained that effective training assists in optimising the utilisation of hospital staff members, which further aids staff members to reach both the hospital's goals and their own individual goals. More importantly, Leonard and Zeace (2011) have argued that an effective training programme should introduce new skills and knowledge to employees, bring about desirable changes in employees' performance, and produce marked benefits to the organisation.

\section{Conclusion and Recommendations}

Successful QMS implementation is a step towards reducing the cost of health care organisations and increasing their productivity and effectiveness. The study explored the means and ways to address QMS obstacles based on the participating hospitals' managers. The suggested solutions are important because they are based on real experience and practice of hospital managers (medical directors, administrative directors, quality managers, and nursing directors). Thus the findings could enhance the effectiveness and efficiency of quality programs in hospitals.

The following recommendations, as derived from this study, can help Jordanian hospitals address challenges related to improving the quality of their services and increasing hospital productivity.

1. Hospitals should reward talented and disciplined employees through good salaries and other benefits. Rewards should not be limited to physicians or specialists but should be extended to all staff working in the hospital. As Jordan is not a wealthy country, hospitals may be unable to provide significant monetary rewards. Therefore, hospitals should consider introducing more non-monetary rewards /benefits such as health insurance, day care options for parents, extra vacation days, or gym memberships to improve staff satisfaction.

2. Decision makers should recruit highly trained specialists in hospital management to run hospitals and /or support existing managers to be trained as specialists in hospital management. Such specialists will be in a position to better plan for the future as well as help hospitals to achieve their QMS goals.

3. Jordanian hospitals should have continuous training programs for all employees and should allocate enough funds to sustain such programs. Training funds should be sufficient to enable each hospital to provide training to newly recruited and existing employees around the enhancement of quality so that all staff members are able to support quality improvement across the hospital.

4. Hospital managers should be encouraged to delegate part of their authority to their staff and should identify the responsibility and accountability required of each staff member. Delegation of authority in hospitals should flow from the top to the bottom, based on the staff members' areas of specialisation and directed towards creating cooperation between the managers and other hospital staff.

5. A key finding of the study was that building a trusting environment in hospitals would be useful in supporting QMS implementation. Hospital managers in Jordan are requested to devise measures to improve efficiency through trust, clear accountability measures and empowering staff to do their best.

6. The adequacy and stability of staff was found to be a mechanism for resolving QMS obstacles. Therefore hospitals should maintain enough staff members through cultivating job satisfaction measures in order to achieve the hospital's goals.

\section{References}

A'aqoulah, A., Kuyini, A., Ajlouni, M., Saif, N., \& Al-Raoush, A. (2016). Staff Perceptions of Obstacles to Quality Management Systems in Low-and High-Performing Hospitals in Jordan. International Journal of Business and Management, 11(2), 232-240. http://dx.doi.org/10.5539/ijbm.v11n2p232

Abdullah, S., Razak, A., Hanafi, M., \& Jaafar, M. (2013). Implementation barriers of ISO 9000 within the Malaysian local government. International Journal of Quality \& Reliability Management, 30(8), 853-876. http://dx.doi.org/10.1108/IJQRM-Dec-2011-0160

Abele, J. (Ed.). (2004). Medical errors and litigation: Investigation and case preparation. Arizona: Lawyers \& Judges 
Publishing Company.

Ajlouni, M. (2010). Human Resource for Health, Country Profile-Jordan, WHO, EMRO, 2011. Retrieved from http://apps.who.int/medicinedocs/documents/s17239e/s17239e.pdf

Colombo, M., \& Delmastro, M. (2004). Delegation of authority in business organisations: an empirical test. The Journal of Industrial Economics, 2(1) 53-80. http://dx.doi.org/10.1111/j.0022-1821.2004.00216.x

DiMaggio, P., \& Powell, W. (1983). The iron Cage revisited: Institutional isomorphism and collective rationality in organisational fields. American Sociological Review, 48, 147-160. http://dx.doi.org/10.2307/2095101

Hauswirth, I. (Ed). (2007). Effective and efficient organisations? government export promotion in Germany and the UK from an organisational economics perspective. Heidelberg: Springer Science \& Business Media.

Kirkpatrick, D. (Ed.). (2009). Evaluating training programs: the four levels. San Francisco: Read How You Want.

Krupa, L., \& Chan, B. (2005). Canadian rural family medicine training programmes growth and variation in recruitment. Canadian Family Physician, 51(6), 852-853.

Lambrou, R., Kontodimopoulos, N., \& Niakas, D. (2010). Motivation and job satisfaction among medical and nursing staff in a Cyprus public general hospital. Human Resources for Health, 8(1), 26-35. http://dx.doi.org/10.1186/1478-4491-8-26

Leonard, N., \& Zeace, N. (Eds.). (2011). Designing training programmes. New York: Routledge.

Lin, C., \& Jang, W. (2008). Successful ISO 9000 implementation in Taiwan, how can we achieve it, and what does it mean? International Journal of Productivity and Performance Management, 57(8), 600-622. http://dx.doi.org/10.1108/17410400810916044

Nanda, V. (Ed.). (2005). Quality management system handbook for product development companies. New York: CRC Press. http://dx.doi.org/10.1201/9781420025309

Natale, S., Wilson, J., \& Perry, L. (Eds.). (2002). The morale manager. New York: Global Academic Publishing.

Nelson, B. (Ed.). (2008). Healthcare staffs' perception of staffing adequacy. Texas: ProQuest.

Oakland, J. (Ed.). (2012). TQM: Text with cases. New York: Routledge.

Perrot, J., \& Roodenbeke, E. (Eds.). (2011). Strategic contracting for health systems and services. New Jersey: Transaction Publishers.

Phillips, J., \& Edwards, L. (Eds.). (2008). Managing talent retention: an ROI approach. New York: John Wiley \& Sons.

Pillay, R. (2008). Managerial competencies of hospital managers in South Africa: a survey of managers in the public and private sectors. Human Resources for Health, 6(4). http://dx.doi.org/10.1186/1478-4491-6-4

Pongpirul, K., Sriratanaban, J., Asavaroengchai, S., Thammatach, J., \& Laoitthi, P. (2006). Comparison of health care professionals' and surveyors' opinions on problems and obstacles in implementing quality management system in Thailand: a national survey. International Journal for Quality in Health Care, 18(5), 346-351. http://dx.doi.org.ezproxy.une.edu.au/10.1093/intqhe/mzl031

Sarawat, S. (2012). Examining the job characteristics: A matter of employees' work motivation and job satisfaction. Journal of Behavior Sciences, 22(2), 13-25.

Wagner, C., Gulacsi, L., Takacs, E., \& Outinen, M. (2006). The implementation of quality management systems in hospitals: a comparison between three countries. BMC Health Services Research, 6(50). http://dx.doi.org/10.1186/1472-6963-6-50

Westphal, J., Gulati, R., \& Shortell, S. (1997). Customization or conformity? An institutional and network perspective on the content and consequences of TQM adoption. Administrative Science Quarterly, 42, 366-394. http://dx.doi.org/10.2307/2393924

Wojnar, M., \& Swanson, M. (2007). Phenomenology: An exploration. Journal of Holistic Nursing, 25(3), 172-180. http://dx.doi.org/10.1177/0898010106295172

\section{Copyrights}

Copyright for this article is retained by the author(s), with first publication rights granted to the journal.

This is an open-access article distributed under the terms and conditions of the Creative Commons Attribution license (http://creativecommons.org/licenses/by/4.0/). 